\title{
Olive Oil Nutraceuticals in the Prevention and Management of Diabetes: From Molecules to Lifestyle
}

\author{
Ahmad Alkhatib ${ }^{1, *(\mathbb{D})}$, Catherine Tsang ${ }^{2}$ and Jaakko Tuomilehto ${ }^{1}$ \\ 1 Dasman Diabetes Institute, Kuwait P.O. Box 1180, Dasman 15462, Kuwait; \\ jaakko.tuomilehto@dasmaninstitute.org \\ 2 Faculty of Health and Social Care, Edge Hill University, St. Helens Road, Ormskirk, Lancashire L39 4QP, UK; \\ Tsangc@edgehill.ac.uk \\ * Correspondence: drahmadalkhatib@gmail.com or ahmad.alkhatib@dasmaninstitute.org; \\ Tel.: +965-2224-2999 (ext. 2213)
}

Received: 23 June 2018; Accepted: 10 July 2018; Published: 12 July 2018

\begin{abstract}
Lifestyle is the primary prevention of diabetes, especially type-2 diabetes (T2D). Nutritional intake of olive oil (OO), the key Mediterranean diet component has been associated with the prevention and management of many chronic diseases including T2D. Several OO bioactive compounds such as monounsaturated fatty acids, and key biophenols including hydroxytyrosol and oleuropein, have been associated with preventing inflammation and cytokine-induced oxidative damage, glucose lowering, reducing carbohydrate absorption, and increasing insulin sensitivity and related gene expression. However, research into the interaction of $\mathrm{OO}$ nutraceuticals with lifestyle components, especially physical activity, is lacking. Promising postprandial effects have been reported when $\mathrm{OO}$ or other similar monounsaturated fatty acids were the main dietary fat compared with other diets. Animal studies have shown a potential anabolic effect of oleuropein. Such effects could be further potentiated via exercise, especially strength training, which is an essential exercise prescription for individuals with T2D. There is also an evidence from in vitro, animal, and limited human studies for a dual preventative role of $\mathrm{OO}$ biophenols in diabetes and cancer, especially that they share similar risk factors. Putative antioxidative and anti-inflammatory mechanisms and associated gene expressions resulting from $\mathrm{OO}$ biophenols have produced paradoxical results, making suggested inferences from dual prevention T2D and cancer outcomes difficult. Well-designed human interventions and clinical trials are needed to decipher such a potential dual anticancer and antidiabetic effects of $\mathrm{OO}$ nutraceuticals. Exercise combined with $\mathrm{OO}$ consumption, individually or as part of a healthy diet is likely to induce reciprocal action for T2D prevention outcomes.
\end{abstract}

Keywords: olive nutraceuticals; functional foods; exercise; nutrition; type-2 diabetes

\section{Introduction}

Diabetes is a major health problem and one of the leading causes of morbidity and mortality worldwide [1]. The current estimated prevalence has already reached over 400 million people [2]. Preventing type 2 diabetes (T2D) is possible mainly through lifestyle adjustments. Large prospective studies have all shown remarkable reductions in T2D incidence through combinations of dietary and physical activity modifications [3,4]. Reduced T2D incidence rates have also been found more recently in the PREDIMED follow up study, which also demonstrated key benefits of the Mediterranean diet (MD) such as adherence in reducing cardiovascular disease and mortality rates [5,6]. Such interest has made it important to review the T2D preventative role of functional foods and bioactive components 
present within MD including vegetables and fruit, olive oil, fish, and tree nuts [7]. Given that olive oil $(\mathrm{OO})$, especially in its extra-virgin form, is the distinct macronutrient lipid and key culinary ingredient characterizing $\mathrm{MD}$, it would be important to review the T2D preventative bioactive ingredients of $\mathrm{OO}$ from molecular to whole body level.

At a molecular level, several bioactive ingredients within $O O$ have been repeatedly linked with anti-oxidant and anti-inflammatory preventative functions, particularly those from monounsaturated fatty acids (MUFA), and key biophenols such as oleuropein and hydroxytyrosol (HT) [8]. The health benefits of $\mathrm{OO}$ in T2D prevention and management continues to be of a growing research interest and a simple search on PubMed using OO and diabetes as keywords revealed 417 entries, and this was increased to 1667 entries with the search of $\mathrm{OO}$ and health. Readers can also refer to recent systematic reviews for virgin $\mathrm{OO}$ effects in T2D prevention [9]. However, there is a lack of research on how $\mathrm{OO}$ and its phenolic components function as part of lifestyle prevention of T2D, especially when combined with enhanced physical activity. Augmenting the benefits of healthy nutritional food components, or functional food, with adding lifestyle approaches such as exercise, can extend a comprehensive model for T2D prevention and management previously presented [7]. This review aims to investigate key molecular components of $\mathrm{OO}$ ingredients and how they interact with lifestyle approaches to prevent disease, especially T2D. It will also discuss recent findings of novel molecular functions of OO, and how they can be augmented in the lifestyle prevention of T2D and associated diseases.

\section{Bioactive Compounds and Key Functions of Olive Oil: Relevance for Diabetes}

Over 30 hydrophillic biophenolic compounds have been identified in $\mathrm{OO}$ derived from the olive tree fruit (Olea europaea L., Oleaceae family), most of which are responsible for the organoleptic properties, bitter and pungent flavours and aromas, and oxidative stability of the oil [10-12]. Biophenols are a diverse and heterogenous group of compounds characterized by an aromatic benzene ring attached to one or more hydroxyl groups in their structure. They are synthesized as secondary plant metabolites via the shikimate, polyketide, and acetate biosynthetic pathways, producing $\mathrm{C} 6-\mathrm{C} 3$, and $\mathrm{C} 6-\mathrm{C} 3-\mathrm{C} 6$ derivatives, and aromatic terpenoids, respectively [13]. Several enzymatic transformations including condensation, cyclisation, glycosylation, hydroxylation, acylation, methylation, and prenylation contribute to the structural diversity of phenylalanine-derived metabolites [14] and tyrosol (4-(2-Hydroxyethyl) phenol), one of the major phenylethanoids derived from OO, which has the ability to form esters with fatty acids [15]. Levels of biophenols in $\mathrm{OO}$ are highly variable and are influenced by several factors including different varietal cultivars, degree of fruit ripening, stage of maturation, storage conditions, and processing methods $[16,17]$. Nonetheless, studies have shown that extra virgin OO (EVOO) contains greater levels of biophenols (ca. $50-800 \mathrm{mg} / \mathrm{kg}$ ) compared with those of refined OO (ca. $62-198 \mathrm{mg} / \mathrm{kg}$ ), which undergo further and more extensive processing [18]. HT (3,4-DHPEA) and tyrosol (p-HPEA) comprise over $90 \%$ of the total phenolic content of OO, in addition to their secoiridoid derivatives-dialdehydic forms of elenolic acid (EA) linked to HT (oleacein: 3,4-DHPEA-EDA) and tyrosol (oleocanthal: p-HPEA-EDA), aglycones of oleuropein (3,4-DHPEA-EA) and ligstroside (p-HPEA-EA). Hydrophilic esters of EA; tyrosol, HT, oleocanthal, and oleuropein, and their associated compounds; 10-hydroxyoleuropein, ligstroside, and 10-hydroxyligstroside are the most prevalent [19]. Lignans; (+)-1-acetoxypinoresinol and (+)-1-hydroxypinoresinol, and their respective glucosides have been detected in the bark of the olive tree, and in OO, and levels have been reported to be in the region of ca. $100 \mathrm{mg} / \mathrm{kg}$ [20]. Phenolic acids; sinapic, vanillic, caffeic, ferulic, p-hydroxybenzoic, p-coumaric acid, protocatechuic acid, and hydroxy-isocromans; 1-phenyl-6,7-dihydroxy-isochroman and 1-(3'-methoxy-4'-hydroxy)-6,7-dihydroxy-isochroman, synthesized from reactions with HT, benzaldehyde, and vanillin, have also been detected in $\mathrm{OO}$, however levels rarely exceed ca. $1 \mathrm{mg} / \mathrm{kg}$ [21]. Similarly, flavonoids, luteolin and apigenin are present in levels much lower in comparison to other phenolics derived from OO [22]. HT, tyrosol, and oleuropein are of scientific 
interest due to their significant effects on several molecular, genetic, and biological mechanisms, which could contribute to the prevention of chronic diseases such as T2D.

Several important biological properties have been ascribed to biophenols derived from OO, including antioxidant; free-radical scavenging and cardio-protective effects, and their ability to modulate pro-inflammatory cytokines and markers of inflammation, which could mitigate modifiable risk factors associated with T2D [23-25]. The cardioprotective role of HT and their derivatives, particularly oleuropein, in their ability to improve high-density lipoproteins (HDL) [26], reduce low-density lipoprotein (LDL), inhibit platelet aggregation, and improve endothelial function [27] are well recognized. Health claims exist in the EU for the role of OO derived biophenols in their protection against the oxidation of blood lipids, and maintenance of normal blood LDL-cholesterol levels [28], and current recommendations suggest a daily intake of ca. $20 \mathrm{~g}$ of EVOO (of which $5 \mathrm{mg}$ is derived from HT and its derivatives) to protect from CVD [29]. Such recommendations do not yet exist for T2D. Evidence from in vitro, in vivo, and clinical studies indicate significant anti-inflammatory effects of HT in their ability to reduce the expression of adhesion and signaling molecules and inflammatory markers [30,31]. These effects are well documented in those at risk for CVD; however, few studies have been tested in people with or at risk of T2D. Nonetheless, OO derived biophenols may reduce postprandial inflammation by decreasing the activation of nuclear-factor kappa B (NF- $\mathrm{KB}$ ) and lipopolysaccharide (LPS) absorption. Camargo et al. [32] administered a virgin OO enriched meal with different concentrations of phenolics (High: 398 ppm, Intermediate: 149 ppm and Low: $70 \mathrm{ppm}$ ) to subjects with metabolic syndrome (MetS) including T2D. Inhibition of NF- $\mathrm{KB}$ and decreased expression of interleukin-IL-1 $\beta$ and IL- 6 was observed following the meal enriched with the highest concentration (398 ppm) of OO. Reduced fasting plasma glucose concentrations, glycated haemoglobin A1c (HbA1c), body weight, and inflammatory adipokines have also been demonstrated in a small-scale study with overweight T2D patients following intake of EVOO (equivalent to $577 \mathrm{mg} / \mathrm{kg}$, mainly as HT) [33]. Phenolics could exert potential anti-diabetic effects due to their potent free-radical scavenging and antioxidative properties. Animal models and in vitro evidence demonstrate their interaction with intracellular signaling pathways, such as nuclear transcription factor (erythroid-derived 2)-like 2 (Nrf2), which is involved in the regulation of the expression of antioxidant proteins that protect against oxidative damage. In vitro studies indicate the potential role of HT and oleuropein in their ability to protect cells against oxidative stress by activating the Nrf2/ARE pathway in a dose-dependent manner, with HT exhibiting potent radical scavenging capacity [34] and ability to upregulate protective enzymes including thioredoxin reductase [35]. Evidence from a recent meta-analysis on OO consumption in T2D patients reported a lower production of advanced glycosylated end-products (AGE's) [9]. HT supplementation (10 mg/ $\mathrm{kg} /$ day for 5 weeks) enhanced glucose tolerance and insulin sensitivity leading to a decrease of homeostatic model assessment-insulin resistance in rat models [36]. Further potential anti-diabetic mechanisms have been demonstrated in experimental in vitro studies for flavonoids and phenolic acids e.g., chlorogenic, ferulic, caffeic, and tannic acids, in their ability to inhibit $\alpha$-amylase, $\alpha$-glucosidase enzymes, and the sodium dependent SGLT1-mediated glucose transport, thus potentially influencing glucose metabolism by inhibiting carbohydrate digestion and absorption [37,38]. HT has a high degree of bioavailability as evidenced by their high rates of absorption following ingestion of EVOO (40-95\%) in humans; oleuropein-glycoside, oleuropein, and ligstroside-aglycones are converted to HT or tyrosol and excreted in urine, and HT and tyrosol themselves are sometimes conjugated to glucuronic acid and excreted in urine as glucuronides [39]. It is also thought that ingestion in this formulation (i.e., oil) could further mitigate their breakdown in the gastrointestinal tract. The mechanisms of absorbing and exerting key OO bioactive compounds may explain its fate and preventative effects in T2D and other cardiometabolic diseases. It is likely that biophenols may influence glucose metabolism via several mechanisms; inhibition of carbohydrate digestion and glucose absorption in the intestine, activation of insulin receptors and glucose uptake in the tissues, antioxidative properties, and immunomodulatory effects. 
Several T2D protective mechanisms of $\mathrm{OO}$ and similar olive leaves biophenols have been reported from cell culture, animal and human studies, and summarized in detail elsewhere [40]. Those include oleuropein effects on reducing amyloid aggregation and preventing inflammation and cytokine-induced oxidative damage of pancreatic $\beta$-cells and enhancing $\beta$-cells capacity; olive leaves extracts effects include lowering glucose and cholesterol levels; modifying gene expression implicated in lipogenesis, thermogenesis and insulin resistance; reducing digestion and intestinal absorption of dietary carbohydrates in the mucosal and in serosal sides of the intestine; reducing $\mathrm{HbA} 1 \mathrm{c}$ and fasting plasma insulin; acutely enhancing insulin sensitivity and related gene expression by $\mathrm{OO}$ ingestion [41]; oleacein preventing inflammatory response and cytokine-mediated oxidative cell damage with downregulation of a number of genes involved in adipocyte differentiation. It is however unclear at this juncture, the precise role of OO biophenols, and further investigations, especially in humans, are necessary to fully elucidate their mechanisms in T2D.

\section{Does Olive Oil Prevent T2D Independently or as Part of a Healthy Diet?}

Attributing health benefits to $\mathrm{OO}$ cannot be investigated in isolation of other healthy dietary and lifestyle components, especially since $\mathrm{OO}$ has been the defined food component characterizing MD, which contains other healthy foods such as seafood, fruits and vegetables, and nuts [42]. However, longitudinal prospective studies which OO to households who consumed MD reported better cardioprotective outcomes compared with MD supplemented with nuts, despite both diets showed better risk-reduction outcomes than low-fat control diet [5]. In the 10-year follow-up of this study, T2D incidence was lower with OO supplemented MD compared with MD supplemented with nuts or low-fat diet control $(80,92$, and 101), and this corresponded to lower hazard ratios (0.60 vs. 0.82) in the MD supplemented with OO compared with the MD with nuts [6]. Another longitudinal study also reported a lower 10-year incidence of T2D and CVD events in prediabetic individuals who had a higher adherence to MD components [43]. However, OO was part of 11 other components in the 55-score Greek MD scales used in the latter compared with OO being part of 9 other components in the Spanish 14-item MD scale used in the PREDIMED follow-up study $[6,44]$. Other MD interventions have also shown relevant improvement in T2D biomarkers and enhanced microvascular and cardiorespiratory outcomes when MD was combined with an 8-week exercise intervention and a one-year follow up, with $\mathrm{OO}$ being the key ingredient implemented as part of the MD 9 components in older adults and postmenopausal women cohorts [45-47]. MD-induced enhancement in endothelial function and markers of vascular inflammation has been associated with improved glucose tolerance in individuals with MetS [48].

In a sub-group of the PREDIMED study follow up (after 1 year), the cardioprotective anti-inflammatory benefits were attributed to $\mathrm{OO}$ only based on lower plasma tumor necrosis factor receptor (TNFR60) concentration found in individuals allocated in the highest tertile of OO and vegetables consumption compared with those in lowest tertile [49]. This was combined by an overall MD-components induced reduction in plasma IL-6, TNFR60, and TNFR80, compared with an increase in those who followed a low-fat diet. Thus, there is convincing evidence that consuming OO as part of a healthy MD diet is protective of T2D in high-risk individuals with prediabetes and those with high CVD risk.

The current evidence from cohort studies on $\mathrm{OO}$ in T2D prevention stems from meta-analyses, which have shown that OO is the key MUFA (55-80\% oleic acid), and that MUFA from vegetable sources are responsible for alleviating T2D metabolic risk factors and reducing all-cause mortality, stroke, and CVD events $[9,25]$. Nevertheless, evidence from randomized controlled trials has often focused on testing the main OO biophenol compounds (oleuropein, tyrosol, HT, flavonoids, and lignans) and other MUFA compounds. These compounds have been reviewed recently for their effectiveness in the prevention of T2D, especially showing increased HDL, enhanced endothelial vascular activity, reduced reliance on carbohydrate substrates, and reduced glucose release from the liver, as well as increased glucose uptake in peripheral tissues, which can reduce $\mathrm{HbA1c}$ [9]. 
When compared with other healthy oils with similar constituents such as a-linoleic acid in rapeseed oil (common in the Nordic diet), OO biophenols, especially oleuropein, have been suggested to be superior in their anti-oxidation and effects on blood lipids [50]. For example, the EPIC-Interact study has shown that phospholipid $\alpha$-linoleic acid (a compound found only in oleic acid of $\mathrm{OO}$ ) is inversely associated with T2D [51]. Further anticancer and cardioprotective properties within $\alpha$-linolenic acid of OO have been suggested to be superior than $\alpha$-linoleic acid found in rapeseed oil, especially when such oils are consumed as part of a healthy diet such as MD [9,50].

\section{New Scope for Olive Oil, Physical Activity, and Lifestyle Approaches in T2D Prevention}

The synergistic effects between healthy food components including $\mathrm{OO}$ and other lifestyle factors, especially physical activity, is integral to the prevention and management of T2D. Better T2D outcomes can be achieved, whether through combining nutritional ingestions with exercise, or with other lifestyle approaches to augment the mechanistic preventative effects of functional foods (i.e., molecular, metabolic, vascular, and behavioral), and has been shown to be effective as part of a model we recently developed for the prevention and management of T2D [52].

However, only a limited number of well-designed studies have tested the effectiveness of $\mathrm{OO}$ synergy with exercise interventions on relevant T2D outcomes. For example, combining 1-h of moderate endurance exercise with consuming an OO breakfast meal (saturated fat $15 \%$ and unsaturated fat $85 \%$ ) produced a $26 \%$ lower postprandial triglyceride (TG) than a butter-no exercise meal (saturated fat $71 \%$ and unsaturated fat 29\%) [53]. Such combined effects suggest positive mechanisms for OO on lipid abnormalities associated with T2D or "diabetic dyslipidemia" such as the high concentration of TG and small dense LDL and a low concentration of HDL cholesterol [54]. Another study using animal models has shown that diets with $\mathrm{OO}$ induced better counteracting benefits to exercise-induced oxidative-stress ( $26 \%$ vs. $17 \%$ increase in the area under the curve) compared with a butter-based diet trial [55]. This suggests that the benefits of OO may be significantly augmented when combined with exercise, due to reciprocal actions on T2D outcomes and exercise-induced oxidative-stress. Other studies encompassing EVOO as part of MD have also shown effectiveness in combining MD with supervised moderate exercise training in enhancing microcirculatory vascular activity in high-risk individuals $[45,46]$. A 6-month multicomponent lifestyle school-based program consisting of four different lifestyle approaches (physical activity, nutrition education, combined with substituting normally taken oil with EVOO) found that glycemic and diastolic blood pressure were reduced in the intervention group who adopted EVOO [56]. OO consumption as part of a health dietary plan is likely to produce better T2D prevention outcomes when combined with exercise, and requires further investigations.

Enhancing the anabolic effects of strength training through novel effects of $\mathrm{OO}$ compounds is another interesting area in T2D prevention, especially given the importance of strength training for patients with T2D patients or those at high-risk [2]. Recent evidence from animal studies indicated novel anabolic enhancing effects of $\mathrm{OO}$ biophenols on androgen function. For example, oleuropein supplementation increased testicular testosterone concentrations, reduced plasma corticosterone, and enhanced plasma LH in rat models [57]. These anabolic effects were observed following the addition of $0.1 \mathrm{~g}$ per $100 \mathrm{~g}$ oleuropein to a high protein (40\%) diet (40,25, and $10 \mathrm{~g}$ per $100 \mathrm{~g}$ casein) levels for 28 days high-protein diet [58].

Oleuropein has also been found to confer a higher resistance to oxidation of EVOO when compared with other healthy oils such as rapeseed oil [50,51]. Whether and how oleuropein potentiates anabolic effects can be enhanced via exercise training is yet to be investigated in T2D prevention.

For example, testosterone deficiency promotes insulin resistance and increases the risk of T2D [59]. Testosterone plays a critical role in the regulation of body composition in males and exhibits potential anti-obesity effects mediated by the androgen receptor (AR) [60]. Emerging research from knockout mice indicates a protective mechanism of AR signaling in adipocytes, critical in the regulation of insulin action and glucose homeostasis, independent of adiposity [61]. This new insight into the 
importance of AR activity may potentially lead to the development of a new multicomponent lifestyle strategy targeted at insulin resistance associated with testosterone deficiency, for which OO could play an important therapeutic role.

In addition to their potential anabolic effects, $\mathrm{OO}$ biophenols may play a role in augmenting strength training outcomes as part of T2D prevention via their putative added modulation of the anti-inflammatory, anti-oxidation, and pro-hypertrophy mechanism, especially when $\mathrm{OO}$ was ingested as part of a dietary plan. A recent rodent study reported an increase in muscle hypertrophy, articular cartilage recovery, and reduced IL-6 in rats with early osteoarthritis when exercise (daily treadmill running 5 days a week for $10 \mathrm{~min}$ ) was combined with ingesting a standardized diet enriched with EVOO for 12 weeks [62]. The combined anti-inflammatory and pro-hypertrophy mechanism induced by conjugated OO jointly with exercise could be effective in preventing and treating T2D and associated complications. For example, reducing inflammatory cytokines could counteract muscle catabolism via actions on monocyte adhesion proteins such as monocyte chemoattractant protein- 1 molecule (MCP1) [63].

In the context of lifestyle T2D prevention, effects of $\mathrm{OO}$ are not exclusive to exercise and diet. Disease-related detriments to other lifestyle behaviors such as sleep disturbance, fatigue, depression, and stiffness have also been shown to improve with $\mathrm{OO}$ combined with exercise intervention in women with fibromyalgia [64]. Such positive synergetic effects of $\mathrm{OO}$ and exercise could be explained by their effect on oxidative stress, especially on reducing inflammatory cytokines IL- 6 and TNF- $\alpha$ [65], which are key biomarkers in T2D prevention and management. Further research is needed to test such synergetic effects in high-risk and T2D individuals. Research in this area is especially important given the promising evidence for augmented T2D preventative effects, when physical activity is combined with selected functional foods and nutraceutical of MD and naturally available health promoting herbs, as summarized elsewhere [7].

Another interesting lifestyle approach is to investigate whether biophenols, including those in $\mathrm{OO}$ can augment physiological exercise performance, especially cardiorespiratory exercise capacity. Enhanced cardiorespiratory fitness is known to associate with disease prevention especially cardio-metabolic disorders [66]. However, a recent review did not provide convincing evidence about the role of biophenols and exercise performance [67]. Quercetin supplementation for 7 days was reported to enhance aerobic capacity and improve exercise time, but the meta-analysis relied on a small number of studies, which used non-OO biophenols and may not apply to this review. Nonetheless, enhancing exercise-dependent outcomes, especially cardio metabolic, through OO supplementation is potentially increasing its effectiveness for T2D prevention when adopted as part of a lifestyle approach.

\section{Diabetes, Cancer Mechanisms and Olive Oil Interrelationship}

The link between hyperinsulinemia, T2D, and cancer is a research area of a growing interest, since there is evidence that people with diabetes are at a significantly higher risk of developing many forms of cancer given their similarities in risk factors and pathophysiology [68]. Some evidence indicates a higher risk of more aggressive and metastatic forms of cancer, with poor prognosis in diabetics $[68,69]$. Plausible biological mechanisms have been described to account for this link including the effects of hyperglycemia, hyperinsulinemia, and inflammation on cancer etiology and progression [70]. Insulin is a growth factor, which stimulates cell mitosis and migration, and inhibits apoptosis, effects that could potentially become exacerbated under conditions of insulin resistance and impairment of insulin-regulated metabolic pathways, as seen in T2D.

Therefore, the potential of $\mathrm{OO}$ as a protective agent in both diabetes and cancer makes it interesting to decipher their underlying mechanisms, and to pave the way to develop effective treatment approaches. Evidence from epidemiological studies indicate a potential role of $\mathrm{OO}$ in the prevention of certain cancers, especially those affecting the breast and colon [71-74]. Potential anti-cancer effects of $\mathrm{OO}$ biophenols have been shown in experimental studies, whereby oleuropein inhibited cancer cell growth and induced apoptosis in human breast cancer cell lines, T-47D, and 
MCF-7 via the p53-dependent pathway and via regulation of Bax and Bcl2 genes [75,76]. Similarly, HT reduces hydrogen peroxide induced DNA damage in human peripheral blood mononuclear cells and promyelocytic leukemia cells (HL60) [77]. The prevention of ROS-induced DNA damage is a potential mechanism of defense against the multistage process of carcinogenesis, and DNA mutations arising from damage caused to DNA is a common feature in carcinogenesis. Pathophysiological manifestations of diabetes, i.e., increased plasma glucose, insulin, AGEs and free fatty acids, enhanced reactive oxygen species (ROS), and oxidative stress, and increased DNA damage, have been reported to be considerably higher in people with poor glycemic control, and diabetes $[78,79]$. Potential anticancer and antidiabetic effects of $\mathrm{OO}$ biophenols are likely mediated, in part, by their potent antioxidant and free radical scavenging properties, and human intervention studies albeit limited, have shown decreased levels of urinary 8-oxo-7,8-dihydro-2'deoxyguanosine (8-OHdG), a known biomarker of DNA damage, after short-term consumption of OO [80].

Secoiridoid from OO especially oleocanthal, have been shown to inhibit the proliferation, migration, and invasion of various human breast, prostate cancer, and multiple myeloma cells [81]. Oleocanthal is the OO compound responsible for the pungent sensation at the back of the throat, is thought to exert similar non-steroidal anti-inflammatory activity to that within ibuprofen, especially in inhibiting harmful cyclooxygenase (COX) 1 and COX2 enzymes [82]. Inhibition of COX2 and matrix metalloproteinases through OO biophenols oleuropein and HT have shown reduced angiogenesis in cultured endothelial cells [83]. Differences in the gene expression profile of breast tissue has also been reported in an animal model of breast cancer susceptibility following ingestion of OO compared with corn oil. Expression of metabolism genes related to mitochondrial uncoupling proteins, were found only after $\mathrm{OO}$ ingestion, suggesting a reduction in the balance of intake and expenditure, alongside a down-regulation of the expression of S100 genes [84] that have been associated with the progression of breast tumorigenesis. The inflammatory transduction of S100 protein signaling is mediated by receptor for advanced glycation end-products (RAGE), in a variety of cell types [85]. RAGE is a multi-ligand cell-surface receptor that propagates cellular dysfunction in several inflammatory disorders, in tumors and in diabetes [86]. It is also a marker for oxidative stress through its interaction with AGEs, where its accelerated formation due to increased concentration of circulating glucose is a feature of T2D [87]. The associated metabolic abnormalities between diabetes and cancer is significant and of clinical importance, and therefore, mandatory counselling and/or screening for changes linked with cancer could be one strategy to accompany lifestyle approaches in patients presenting with obesity, pre-diabetes, and diabetes.

Evidence from in vitro, animal, and limited human studies suggest potential benefit of $\mathrm{OO}$ biophenols via putative anti-oxidative and anti-inflammatory mechanisms involving NF- $\mathrm{kB}$ inhibition with COX-2, IL-6, IL-8, and IL-1 $\beta$ (down-stream products of NF- $\kappa B$ ) expressed at lower levels. These may account for the lower prevalence of cancer in people consuming a MD. However, there is a long way still before such mechanisms are deciphered for each disease. For example, improving insulin sensitivity by inducing the inhibition of NFkB expression is also thought to mediate muscle wasting seen with disuse, denervation, and some systemic diseases (i.e., cancer, sepsis) [88]. High phenolic content OO has been shown to inhibit NF- $\mathrm{KB}$ and decrease IL-1 $\beta$ and IL-6 postprandially in individuals with MetS [31]. Clinical evidence showing dual antidiabetic and anticancer effects is limited and somewhat inconclusive, however intervention studies have reported some benefit of $\mathrm{OO}$ mostly based on changes in biomarkers associated with immunomodulatory and anti-oxidative capacity in healthy, diabetic, and cancer patients $[32,49,80,89,90]$ (Table 1$)$. However, these findings remain inconsistent and this could be due in part to a lack of robust and well-designed clinical trials. 
Table 1. Potential antidiabetic and anticancer dual effects of olive oil in human studies.

\begin{tabular}{|c|c|c|c|}
\hline Reference & Patients & Dose and Formulation & Outcomes \\
\hline Carmargo et al. [32] & $\begin{array}{l}n 49 \text { with MetS, age range: } \\
36-71 \text { years old ( } 19 \text { men, } \\
30 \text { women); mean BMI: } \\
38.59 \pm 0.58 \mathrm{~kg} / \mathrm{m}^{2}\end{array}$ & $\begin{array}{l}40 \mathrm{~mL} \text { VOO intake over } 24 \mathrm{~h} \text {, } \\
\text { provided as a breakfast of high } \\
(398 \mathrm{ppm}), \text { intermediate } \\
(149 \mathrm{ppm}) \text { or low }(70 \mathrm{ppm}) \mathrm{TP}\end{array}$ & $\begin{array}{l}\text { High dose: Decrease NF-kB, } \\
\text { IL-6, TLR4 protein, } \\
\text { IL-1 } \beta \text { expression } \\
\text { Low dose: Increase NF-kB p65 } \\
\text { subunit, IL-6; TLR4 protein, } \\
\text { TNF- } \alpha \text {. }\end{array}$ \\
\hline Urpi-Sarda et al. [49] & $\begin{array}{l}n 106 \text { sub-cohort at high risk of } \\
\text { CVD, from the PREDIMED trial }\end{array}$ & $\begin{array}{l}\text { VOO }(1 \mathrm{~L} / \text { week }) \text { compared with } \\
\text { a control low-fat diet at } 3 \\
\text { months and } 1 \text { year old follow-up }\end{array}$ & $\begin{array}{l}\text { At } 3 \text { months: Reduced IL-6 and } \\
\text { CRP with VOO } \\
\text { At } 1 \text { y: Reduced TNFR 60, } \\
\text { IL-6, TNFR } 80 \\
\text { Increase: IL-6, TNFR60, TNFR80 } \\
\text { with low-fat diet }\end{array}$ \\
\hline Weinbrenner et al. [80] & $\begin{array}{l}n 12 \text { Healthy men, age range: } \\
20-22 \mathrm{y}, \text { mean BMI: } \\
22.9 \pm 1.7 \mathrm{~kg} / \mathrm{m}^{2}\end{array}$ & $\begin{array}{l}25 \mathrm{~mL} / \text { day VOO: Subjects } \\
\text { received } 1 \text { of the } 3 \text { treatments } \\
(25 \mathrm{~mL} / \mathrm{d}) \text { over } 4 \text { days with a } \\
\text { washout period of } 10 \mathrm{~d} \text { between } \\
\text { treatments. low, moderate and } \\
\text { high TP content } \\
(10-486 \mathrm{mg} / \mathrm{kg} \mathrm{TP})\end{array}$ & $\begin{array}{l}\text { Decrease: } 8 \text {-oxo-dG in } \\
\text { mitochondrial DNA and urine, } \\
\text { MDA in urine } \\
\text { Increase: GSH-Px } \\
\text { No effect: GR }\end{array}$ \\
\hline De Bock et al. 2013 [89] & $\begin{array}{l}n 46 \text { Overweight patients, mean } \\
\text { BMI: } 28.0 \pm 2.0 \mathrm{~kg} / \mathrm{m}^{2}\end{array}$ & $\begin{array}{l}\text { OLE provided as capsules } \\
\text { containing } 51.1 \mathrm{mg} \text { oleuropein } \\
\text { and } 9.7 \mathrm{mg} \mathrm{HT}\end{array}$ & $\begin{array}{l}28 \% \text { Increase Beta cell function } \\
\text { Increase: IL- } 6 \\
\text { No effect: IL- } 8 \text {, TNF- } \alpha \text {, } \\
\text { high-sensitive CRP }\end{array}$ \\
\hline Oliveras-López et al. [90] & $\begin{array}{l}n 45 \text { healthy men and women } \\
\text { (age: } 21-45 \text { years old), mean } \\
\text { BMI: } 21.4 \pm 0.5 \mathrm{~kg} / \mathrm{m}^{2}\end{array}$ & $\begin{array}{l}50 \mathrm{~mL} \text { EVOO for } 30 \text { days, two } \\
\text { doses ingested at breakfast ( } 30 \\
\mathrm{~mL}) \text { and lunch }(20 \mathrm{~mL})\end{array}$ & $\begin{array}{l}\text { Increase: Plasma AOX capacity, } \\
\text { AOX enzymes-CAT, GPX; } \\
\text { improved gene expression SOD }\end{array}$ \\
\hline
\end{tabular}

AOX: antioxidant; VOO: virgin olive oil; EVOO: extra virgin olive oil; OLE: olive oil leaf extract; 8-oxo-dG: 8-oxo-7,8-dihydro-2'deoxyguanosine; GR: glutathione reductase; HT: hydroxytyrosol; GSH-Px: glutathione peroxidase; IL-6: interleukin-6; IL-1B: interleukin-1beta; CRP: C-reactive protein; MDA: malonaldehyde; NF- $\mathrm{B}$ : nuclear factor kappa B; ROS: reactive oxygen species; SOD: superoxide dismutase; TLR4: toll-like receptor 4; TNF- $\alpha$ : tumor necrosis factor-alpha; TP: total phenolics.

\section{Conclusions}

Lifestyle prevention of T2D necessitates investigating nutritional dietary bioactive compounds. OO intake as part of the diet has been associated with the prevention and management of T2D. OO contains an abundance of biophenols; oleuropein, HT and their derivatives, and several antidiabetic mechanisms have been ascribed to their potential immunomodulatory, antiproliferative, antioxidative, and anabolic effects. There is a promising evidence that such effects can be further augmented with combining physical activity lifestyle components with $\mathrm{OO}$ consumption. OO mechanisms have mainly emanated from in vitro studies and animal models, with limited clinical studies. Nonetheless, their potential effects on T2D and associated comorbidities is encouraging, such as the potential dual diabetes and cancer protective role found in OO nutraceuticals (Figure 1). Robust human intervention and clinical trials are necessary to fully elucidate the role of $\mathrm{OO}$ in T2D and their associated comorbidities, especially when combined with exercise. 

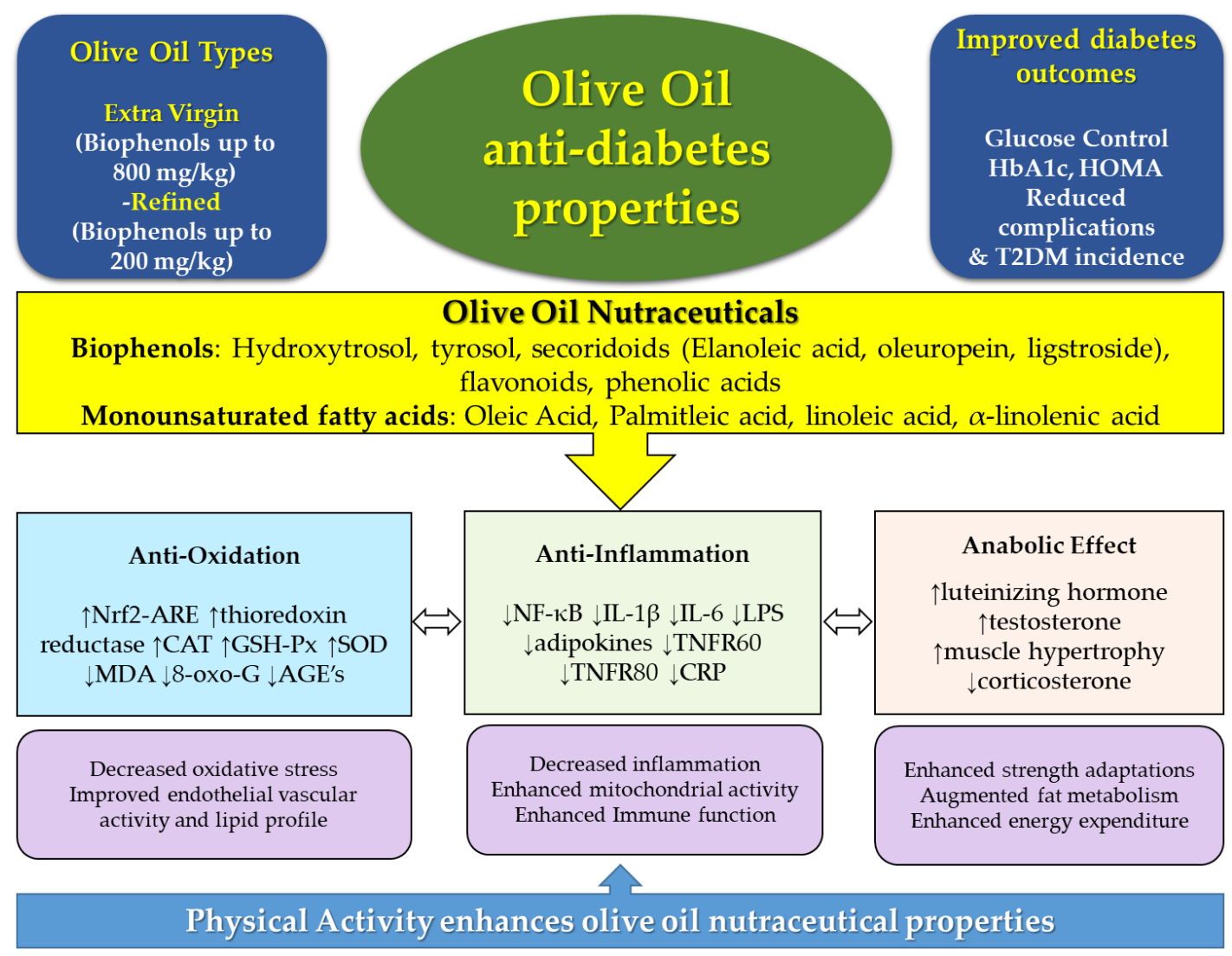

Figure 1. Olive oil, types, and phenolic compounds, and associated diabetes protective molecular mechanisms, which can potentially be augmented with physical activity. AGE's: Advanced glycated end-products; CAT: catalase; CRP: c-reactive protein; Hb1Ac: glycated haemoglobin; GSH-Px: glutathione peroxidase; IL: interleukin; LPS: lipopolysaccharide; MDA: malonaldehyde; SOD: superoxide dismutase; TNFR: tumor necrosis factor receptor. Arrows within caption indicate decrease $(\downarrow)$ or increase $(\uparrow)$.

Author Contributions: A.A. conceived the idea, fully wrote the manuscript, and critically led its coordination. C.T. contributed to writing the manuscript. J.T. contributed to critical editing the manuscript. All authors approved the final version before submitting.

Funding: No funding supported this manuscript.

Acknowledgments: We thank the Dasman Diabetes Institute, Research Division, Kuwait for covering the open access cost to publish this manuscript.

Conflicts of Interest: The authors declare no conflicts of interest.

\section{Abbreviations}

AGEs Advanced glycosylated end products

AR Androgen receptor

ARE Antioxidant response element

Bax, Bc12 Apoptosis regulator genes

COX Cyclooxygenase

CRP C-reactive protein

CVD Cardiovascular disease 


$\begin{array}{ll}\text { EA } & \text { Elenolic acid } \\ \text { GSH-Px } & \text { Glutathione peroxidase } \\ \text { HbA1c } & \text { Haemoglobin A1c } \\ \text { HDL } & \text { High-density lipoprotein } \\ \text { HT } & \text { Hydroxytyrosol } \\ \text { HL60 } & \text { Leukemia cell line } \\ \text { IL } & \text { Interleukin } \\ \text { LDL } & \text { Low-density lipoprotein } \\ \text { LPS } & \text { Lipopolysaccharide } \\ \text { T2D } & \text { Type 2 diabetes } \\ \text { OO } & \text { Olive oil } \\ \text { 8-OHdG } & \text { 8-oxo-7,8-dihydro-2'-deoxyguanosine } \\ \text { MCF-7 } & \text { Breast cancer cell line } \\ \text { MCP1 } & \text { Monocyte chemoattractant protein-1 } \\ \text { MD } & \text { Mediterranean diet } \\ \text { MDA } & \text { Malonaldehyde } \\ \text { MetS } & \text { Metabolic syndrome } \\ \text { MUFA } & \text { Monounsaturated fatty acids } \\ \text { NF- } \text { B } & \text { Nuclear-factor kappa B } \\ \text { Nrf2 } & \text { Nuclear transcription factor } \\ & \text { (erythroid-derived-2)-like 2 } \\ \text { PMBC } & \text { Peripheral blood mononuclear cells } \\ \text { P53 } & \text { Tumor protein antigen } \\ \text { RAGE } & \text { Receptor for advanced glycation end products } \\ \text { ROS } & \text { Reactive oxygen species } \\ \text { SGLT-1 } & \text { Sodium dependent mediated glucose transporter } \\ \text { SOD } & \text { Superoxide dismutase } \\ \text { TNF } \alpha & \text { Tumor necrosis factor alpha } \\ \text { TNFR60 } & \text { Tumor necrosis factor receptor } \\ \text { T-47D } & \text { Breast cancer cell line } \\ & \end{array}$

\section{References}

1. WHO. World Health Organization (WHO) Global Report on Diabetes. 2016. Available online: http://www. who.int/diabetes/global-report/en/ (accessed on 12 September 2017).

2. IDF Diabetes Atlas. 2015. Available online: http://www.diabetesatlas.org/ (accessed on 12 September 2017).

3. Knowler, W.C.; Barrett-Connor, E.; Fowler, S.E.; Hamman, R.F.; Lachin, J.M.; Walker, E.A.; Nathan, D.M. Reduction in the incidence of type 2 diabetes with lifestyle intervention or metformin. N. Engl. J. Med. 2002, 346, 393-403. [CrossRef] [PubMed]

4. Tuomilehto, J.; Lindström, J.; Eriksson, J.G.; Valle, T.T.; Hämäläinen, H.; Ilanne-Parikka, P.; Keinänen-Kiukaanniemi, S.; Laakso, M.; Louheranta, A.; Rastas, M.; et al. Finnish Diabetes Prevention Study Group. Prevention of type 2 diabetes mellitus by changes in lifestyle among subjects with impaired glucose tolerance. N. Engl. J. Med. 2001, 344, 1343-1350. [CrossRef] [PubMed]

5. $\quad$ Estruch, R.; Ros, E.; Salas-Salvado, J.; Covas, M.I.; Corella, D.; Aros, F.; Gomez-Gracia, E.; Ruiz-Gutierrez, V.; Fiol, M.; Lapetra, J.; et al. Primary prevention of cardiovascular disease with a Mediterranean diet. N. Engl. J. Med. 2013, 368, 1279-1290. [CrossRef] [PubMed]

6. Salas-Salvadó, J.; Bulló, M.; Estruch, R.; Ros, E.; Covas, M.I.; Ibarrola-Jurado, N.; Corella, D.; Arós, F.; Gómez-Gracia, E.; Ruiz-Gutiérrez, V.; et al. Prevention of diabetes with Mediterranean diets: A subgroup analysis of a randomized trial. Ann. Intern. Med. 2014, 160, 1-10. [CrossRef] [PubMed]

7. Alkhatib, A.; Tsang, C.; Tiss, A.; Bahorun, T.; Arefanian, H.; Barake, R.; Khadir, A.; Tuomilehto, J. Functional foods and lifestyle approaches for diabetes prevention and management. Nutrients 2017, 9, 1310. [CrossRef] [PubMed] 
8. Gorzynik-Debicka, M.; Przychodzen, P.; Cappello, F.; Kuban-Jankowska, A.; Marino Gammazza, A.; Knap, N.; Wozniak, M.; Gorska-Ponikowska, M. Potential health benefits of olive oil and plant polyphenols. Int. J. Mol. Sci. 2018, 19, e686. [CrossRef] [PubMed]

9. Schwingshackl, L.; Lampousi, A.M.; Portillo, M.P.; Romaguera, D.; Hoffmann, G.; Boeing, H. Olive oil in the prevention and management of type 2 diabetes mellitus: A systematic review and meta-analysis of cohort studies and intervention trials. Nutr. Diabetes 2017, 7, e262. [CrossRef] [PubMed]

10. Genovese, A.; Caporaso, N.; Villani, V.; Paduano, A.; Sacchi, R. Olive oil phenolic compounds affect the release of aroma compounds. Food Chem. 2015, 81, 284-294. [CrossRef] [PubMed]

11. Bendini, A.; Cerretani, L.; Carrasco-Pancorbo, A.; Gómez-Caravaca, A.M.; Segura-Carretero, A.; Fernández-Gutiérrez, A.; Lercker, G. Phenolic molecules in virgin olive oils: A survey of their sensory properties, health effects, antioxidant activity and analytical methods. An overview of the last decade. Molecules 2007, 12, 1679-1719. [CrossRef] [PubMed]

12. Cicerale, S.; Conlan, X.A.; Sinclair, A.J.; Keast, R.S. Chemistry and health of olive oil phenolics. Crit. Rev. Food Sci. Nutr. 2009, 49, 218-236. [CrossRef] [PubMed]

13. Knaggs, A. The biosynthesis of shikimate metabolites. Nat. Prod. Rep. 2001, 18, 334-355. [CrossRef] [PubMed]

14. Noel, J.P.; Austin, M.B.; Bomati, E.K. Structure-function relationships in plant phenylpropanoid biosynthesis. Curr. Opin. Plant Biol. 2005, 8, 249-253. [CrossRef] [PubMed]

15. Ricardo, L.; Comelles, F.; Alcántara, D.; Maldonado, O.S.; Curcuroze, M.; Parra, J.L.; Morales, J.C. Surface-active properties of lipophilic antioxidants tyrosol and hydroxytyrosol fatty acid esters: A potential explanation for the non-linear hypothesis of the antioxidant activity in oil-in-water emulsions. J. Agric. Food Chem. 2010, 58, 8021-8026.

16. Gómez-Rico, A.; Inarejos-García, A.M.; Salvador, M.D.; Fregapane, G. Effect of malaxation conditions on phenol and volatile profiles in olive paste and the corresponding virgin olive oils (Olea europaea L. Cv. Cornicabra). J. Agric. Food Chem. 2009, 57, 3587-3595. [CrossRef] [PubMed]

17. Krichene, D.; Salvador, M.D.; Fregapane, G. Stability of virgin olive oil phenolic compounds during long-term storage (18 months) at temperatures of 5-50 ${ }^{\circ} \mathrm{C}$. J. Agric. Food Chem. 2015, 6, 6779-6786. [CrossRef] [PubMed]

18. Perona, J.S.; Cabello-Moruno, R.; Ruiz-Gutierrez, V. The role of virgin olive oil components in the modulation of endothelial function. J. Nutr. Biochem. 2006, 17, 429-445. [CrossRef] [PubMed]

19. Cicerale, S.; Lucas, L.; Keast, R. Biological activities of phenolic compounds present in virgin olive oil. Int. J. Mol. Sci. 2010, 11, 458-479. [CrossRef] [PubMed]

20. Antonini, E.; Farina, A.; Scarpa, E.S.; Frati, A.; Ninfali, P. Quantity and quality of secoiridoids and lignans in extra virgin olive oils: The effect of two- and three-way decanters on Leccino and Raggiola olive cultivars. Int. J. Food Sci. Nutr. 2016, 67, 9-15. [CrossRef] [PubMed]

21. Lopes de Souza, P.A.; Marcadenti, A.; Lúcia Portal, V. Effects of olive oil phenolic compounds on inflammation in the prevention and treatment of coronary artery disease. Nutrients 2017, 9, 1087. [CrossRef] [PubMed]

22. Carrasco-Pancorbo, A.; Gómez-Caravaca, A.M.; Cerretani, L.; Bendini, A.; Segura-Carretero, A.; Fernández-Gutiérrez, A. A simple and rapid electrophoretic method to characterize simple phenols, lignans, complex phenols, phenolic acids, and flavonoids in extra-virgin olive oil. J. Sep. Sci. 2006, 29, 2221-2233. [CrossRef] [PubMed]

23. Del Carlo, M.; Sacchetti, G.; Di Mattia, C.; Compagnone, D.; Mastrocola, D.; Liberatore, L.; Cichelli, A. Contribution of the phenolic fraction to the antioxidant activity and oxidative stability of olive oil. J. Agric. Food Chem. 2004, 52, 4072-4079. [CrossRef] [PubMed]

24. Owen, R.W.; Mier, W.; Giacosa, A.; Hull, W.E.; Spiegelhalder, B.; Bartsch, H. Phenolic compounds and squalene in olive oils: The concentration and antioxidant potential of total phenols, simple phenols, secoiridoids, lignans and squalene. Food Chem. Toxicol. 2000, 38, 647-659. [CrossRef]

25. Schwingshackl, L.; Hoffmann, G. Monounsaturated fatty acids, olive oil and health status: A systematic review and meta-analysis of cohort studies. Lipids Health Dis. 2014, 13, 154. [CrossRef] [PubMed]

26. Hernáez, Á.; Fernández-Castillejo, S.; Farràs, M.; Catalán, Ú.; Subirana, I.; Montes, R.; Solà, R.; Muñoz-Aguayo, D.; Gelabert-Gorgues, A.; Díaz-Gil, Ó.; et al. Olive oil polyphenols enhance high-density lipoprotein function in humans: A randomized controlled trial. Arterioscler. Thromb. Vasc. Biol. 2014, 34, 2115-2119. [CrossRef] [PubMed] 
27. Moreno-Luna, R.; Muñoz-Hernandez, R.; Miranda, M.L.; Costa, A.F.; Jimenez-Jimenez, L.; Vallejo-Vaz, A.J.; Muriana, F.J.; Villar, J.; Stiefel, P. Olive oil polyphenols decrease blood pressure and improve endothelial function in young women with mild hypertension. Am. J. Hypertens. 2012, 25, 1299-1304. [CrossRef] [PubMed]

28. Schwingshackl, L.; Christoph, M.; Hoffmann, G. Effects of olive oil on markers of inflammation and endothelial function. A systematic review and meta-analysis. Nutrients 2015, 7, 7651-7675. [CrossRef] [PubMed]

29. European Food Safety Authority. Scientific Opinion on the substantiation of health claims related to polyphenols in olive. EFSA J. 2011, 9, 2033. [CrossRef]

30. Manna, C.; Napoli, D.; Cacciapuoti, P.; Porcelli, M.; Zappia, V. Olive oil phenolic compounds inhibit homocysteine-induced endothelial cell adhesion regardless of their different antioxidant activity. J. Agric. Food Chem. 2009, 57, 3478-3482. [CrossRef] [PubMed]

31. Castañer, O.; Covas, M.I.; Khymenets, O.; Nyyssonen, K.; Konstantinidou, V.; Zunft, H.F.; de la Torre, R.; Muñoz-Aguayo, D.; Vila, J.; Fitó, M. Protection of LDL from oxidation by olive oil polyphenols is associated with a downregulation of CD40-ligand expression and its downstream products in vivo in humans. Am. J. Clin. Nutr. 2012, 95, 1238-1244. [CrossRef] [PubMed]

32. Camargo, A.; Rangel-Zuñiga, O.A.; Haro, C.; Meza-Miranda, E.R.; Peña-Orihuela, P.; Meneses, M.E.; Marin, C.; Yubero-Serrano, E.M.; Perez-Martinez, P.; Delgado-Lista, J.; et al. Olive oil phenolic compounds decrease the postprandial inflammatory response by reducing postprandial plasma lipopolysaccharide levels. Food Chem. 2014, 162, 161-171. [CrossRef] [PubMed]

33. Santangelo, C.; Filesi, C.; Varì, R.; Scazzocchio, B.; Filardi, T.; Fogliano, V.; D'Archivio, M.; Giovannini, C.; Lenzi, A.; Morano, S.; et al. Consumption of extra-virgin olive oil rich in phenolic compounds improves metabolic control in patients with type 2 diabetes mellitus: A possible involvement of reduced levels of circulating visfatin. J. Endocrinol. Investig. 2016, 39, 1295-1301. [CrossRef] [PubMed]

34. Visioli, F.; Bellomo, G.; Galli, C. Free radical-scavenging properties of olive oil polyphenols. Biochem. Biophys. Res. Commun. 1998, 247, 60-64. [CrossRef] [PubMed]

35. Peng, S.; Zhang, B.; Yao, J.; Duan, D.; Fang, J. Dual protection of hydroxytyrosol, an olive oil polyphenol, against oxidative damage in PC12 cells. Food Funct. 2015, 6, 2091-2100. [CrossRef] [PubMed]

36. Pirozzi, C.; Lama, A.; Simeoli, R.; Paciello, O.; Pagano, T.B.; Mollica, M.P.; Di Guida, F.; Russo, R.; Magliocca, S.; Canani, R.B.; et al. Hydroxytyrosol prevents metabolic impairment reducing hepatic inflammation and restoring duodenal integrity in a rat model of NAFLD. J. Nutr. Biochem. 2016, 30, 108-115. [CrossRef] [PubMed]

37. Narita, Y.; Inouye, K. Kinetic analysis and mechanism on the inhibition of chlorogenic acid and its components against porcine pancreas alpha-amylase isozymes I and II. J. Agric. Food Chem. 2009, 57, 9218-9225. [CrossRef] [PubMed]

38. Welsch, C.A.; Lachance, P.; Wasserman, B.P. Effects of native and oxidized phenolic compounds on sucrase activity in rat brush border membrane vesicles. J. Nutr. 1989, 119, 1737-1740. [CrossRef] [PubMed]

39. Visioli, F.; Galli, C.; Bornet, F.; Mattei, A.; Patelli, R.; Galli, G.; Caruso, D. Olive oil phenolics are dose-dependently absorbed in humans. FEBS Lett. 2000, 468, 159-160. [CrossRef]

40. Rigacci, S.; Stefani, M. Nutraceutical properties of olive oil polyphenols. An itinerary from cultured cells through animal models to humans. Int. J. Mol. Sci. 2016, 17, 843. [CrossRef] [PubMed]

41. Konstantinidou, V.; Kymenets, O.; Covas, M.I.; de la Torre, R.; Muñoz-Aguayo, D.; Anglada, R.; Farré, M.; Fito, M. Time course of changes in the expression of insulin sensitivity genes after an acute load of virgin olive oil. OMICS 2009, 13, 431-438. [CrossRef] [PubMed]

42. Trichopoulou, A.; Martínez-González, M.A.; Tong, T.Y.; Forouhi, N.G.; Khandelwal, S.; Prabhakaran, D.; Mozaffarian, D.; de Lorgeril, M. Definitions and potential health benefits of the Mediterranean diet: Views from experts around the world. BMC Med. 2014, 24, 112. [CrossRef] [PubMed]

43. Filippatos, T.D.; Panagiotakos, D.B.; Georgousopoulou, E.N.; Pitaraki, E.; Kouli, G.M.; Chrysohoou, C.; Tousoulis, D.; Stefanadis, C.; Pitsavos, C. ATTICA study group. Mediterranean diet and 10-year (2002-2012) incidence of diabetes and cardiovascular disease in participants with prediabetes: The ATTICA study. Rev. Diabet. Stud. 2016, 13, 226-235. [CrossRef] [PubMed] 
44. Martinez-Gonzalez, M.A.; Garcia-Arellano, A.; Toledo, E.; Salas-Salvado, J.; Buil-Cosiales, P.; Corella, D.; Covas, M.I.; Schroder, H.; Aros, F.; Gomez-Gracia, E.; et al. A 14-item Mediterranean diet assessment tool and obesity indexes among high-risk subjects: The PREDIMED trial. PLoS ONE 2012, 7, e43134. [CrossRef] [PubMed]

45. Alkhatib, A.; Klonizakis, M. Effects of exercise training and Mediterranean diet on vascular risk reduction in post-menopausal women. Clin. Hemorheol. Microcirc. 2014, 57, 33-47. [CrossRef] [PubMed]

46. Klonizakis, M.; Alkhatib, A.; Middleton, G.; Smith, M.F. Mediterranean diet-and exercise-induced improvement in age-dependent vascular activity. Clin. Sci. 2013, 124, 579-587. [CrossRef] [PubMed]

47. Klonizakis, M.; Alkhatib, A.; Middleton, G. Long-term effects of an exercise and Mediterranean diet intervention in the vascular function of an older, healthy population. Microvasc. Res. 2014, 95, 103-107. [CrossRef] [PubMed]

48. Esposito, K.; Marfella, R.; Ciotola, M.; Di Palo, C.; Giugliano, F.; Giugliano, G.; D’Armiento, M.; D'Andrea, F.; Giugliano, D. Effect of a mediterranean-style diet on endothelial dysfunction and markers of vascular inflammation in the metabolic syndrome: A randomized trial. JAMA 2004, 292, 1440-1446. [CrossRef] [PubMed]

49. Urpi-Sarda, M.; Casas, R.; Chiva-Blanch, G.; Romero-Mamani, E.S.; Valderas-Martinez, P.; Arranz, S.; Andres-Lacueva, C.; Llorach, R.; Medina-Remon, A.; Lamuela-Raventos, R.M.; et al. Virgin olive oil and nuts as key foods of the Mediterranean diet effects on inflammatory biomarkers related to atherosclerosis. Pharmacol. Res. 2012, 65, 577-583. [CrossRef] [PubMed]

50. Hoffman, R.; Gerber, M. Can rapeseed oil replace olive oil as part of a Mediterranean-style diet? Br. J. Nutr. 2014, 112, 1882-1895. [CrossRef] [PubMed]

51. Forouhi, N.G.; Imamura, F.; Sharp, S.J.; Koulman, A.; Schulze, M.; Zheng, J.; Ye, Z.; Sluijs, I.; Guevara, M.; Huerta, J.M.; et al. Association of plasma phospholipid n-3 and n-6 polyunsaturated fatty acids with type 2 diabetes: The EPIC-InterAct Case-Cohort Study. PLoS Med. 2016, 13, e1002094. [CrossRef] [PubMed]

52. Alkhatib, A.; Tuomilehto, J. Lifestyle Diabetes Prevention. In Encyclopaedia of Endocrine Diseases, 2nd ed.; Huhtaniemi, I., Martini, L., Eds.; Elsevier: Amsterdam, The Netherlands, 2018; ISBN 978-0-12-812200-6.

53. Sasahara, C.; Burns, S.F.; Miyashita, M.; Stensel, D.J. Beneficial effects of combined olive oil ingestion and acute exercise on postprandial TAG concentrations in healthy young women. Br. J. Nutr. 2012, 108, 1773-1779. [CrossRef] [PubMed]

54. Bitzur, R.; Cohen, H.; Kamari, Y.; Shaish, A.; Harats, D. Triglycerides and HDL cholesterol: Stars or second leads in diabetes? Diabetes Care 2009, 32 (Suppl. 2), S373-S377. [CrossRef] [PubMed]

55. Musumeci, G.; Maria Trovato, F.; Imbesi, R.; Castrogiovanni, P. Effects of dietary extra-virgin olive oil on oxidative stress resulting from exhaustive exercise in rat skeletal muscle: A morphological study. Acta Histochem. 2014, 116, 61-69. [CrossRef] [PubMed]

56. Muros, J.; Zabala, M.; Oliveras-López, M.J.; Bouzas, P.R.; Knox, E.; Rufián-Henares, J.Á.; López-García de la Serrana, H. Effect of physical activity, nutritional education, and consumption of extra virgin olive oil on lipid, physiological, and anthropometric profiles in a pediatric population. J. Phys. Act. Health 2015, 12, 1245-1252. [CrossRef] [PubMed]

57. Alhazza, I.M.; Bashandy, S.A.E. Hypoglycemic, hypolipidemic, antioxidant and male sexual improvement potentials of olive oil in alloxan treated rats. J. Pharmacol. Toxicol. 2007, 2, 427-436.

58. Oi-Kano, Y.; Kawada, T.; Watanabe, T.; Koyama, F.; Watanabe, K.; Senbongi, R.; Iwai, K. Oleuropein supplementation increases urinary noradrenaline and testicular testosterone levels and decreases plasma corticosterone level in rats fed high-protein diet. J. Nutr. Biochem. 2013, 24, 887-893. [CrossRef] [PubMed]

59. Kapoor, D.; Malkin, C.J.; Channer, K.S.; Jones, T.H. Androgens, insulin resistance and vascular disease in men. Clin. Endocrinol. 2005, 63, 239-250. [CrossRef] [PubMed]

60. Bojesen, A.; Kristensen, K.; Birkebaek, NH.; Fedder, J.; Mosekilde, L.; Bennett, P.; Laurberg, P.; Frystyk, J.; Flyvbjerg, A.; Christiansen, J.S.; Gravholt, C.H. The metabolic syndrome is frequent in Klinefelter's syndrome and is associated with abdominal obesity and hypogonadism. Diabetes Care 2006, 29, 1591-1598. [CrossRef] [PubMed]

61. McInnes, K.J.; Smith, L.B.; Hunger, N.I.; Saunders, P.T.K.; Andrew, R.; Walker, B. Deletion of the androgen receptor in adipose tissue in male mice elevates retinol binding protein 4 and reveals independent effects on visceral fat mass and on glucose homeostasis. Diabetes 2012, 61, 1072-1081. [CrossRef] [PubMed] 
62. Szychlinska, M.A.; Castrogiovanni, P.; Trovato, F.M.; Nsir, H.; Zarrouk, M.; Lo Furno, D.; Di Rosa, M.; Imbesi, R.; Musumeci, G. Physical activity and Mediterranean diet based on olive tree phenolic compounds from two different geographical areas have protective effects on early osteoarthritis, muscle atrophy and hepatic steatosis. Eur. J. Nutr. 2018. [CrossRef] [PubMed]

63. Lim, J.P.; Leung, B.P.; Ding, Y.Y.; Tay, L.; Ismail, N.H.; Yeo, A.; Yew, S.; Chong, M.S. Monocyte chemoattractant protein-1: A proinflammatory cytokine elevated in sarcopenic obesity. Clin. Interv. Aging 2015, 10, 605-609. [CrossRef] [PubMed]

64. Rus, A.; Molina, F.; Ramos, M.M.; Martinez-Ramirez, M.J.; Del Moral, M.L. Extra virgin olive oil improves oxidative stress, functional capacity, and health-related psychological status in patients with fibromyalgia: A preliminary study. Biol. Res. Nurs. 2016, 19, 106-115. [CrossRef] [PubMed]

65. Yarla, N.S.; Polito, A.; Peluso, I. Effects of olive oil on TNF- $\alpha$ and IL-6 in humans: Implication in obesity and frailty. Endocr. Metab. Immune Disord. Drug Targets 2018, 18, 63-74. [CrossRef] [PubMed]

66. Blair, S.N.; Brodney, S. Effects of physical inactivity and obesity on morbidity and mortality: Current evidence and research issues. Med. Sci. Sports Exerc. 1999, 31, S646-S662. [CrossRef] [PubMed]

67. Somerville, V.; Bringans, C.; Braakhuis, A. Polyphenols and Performance: A systematic review and meta-analysis. Sports Med. 2017, 7, 1589-1599. [CrossRef] [PubMed]

68. Johnson, J.A.; Carstensen, B.; Witte, D.; Bowker, S.L.; Lipscombe, L.; Renehan, A.G. Diabetes and cancer (1): Evaluating the temporal relationship between type 2 diabetes and cancer incidence. Diabetologia 2012, 55, 1607-1618. [CrossRef] [PubMed]

69. Vigneri, P.; Frasca, F.; Sciacca, L.; Pandini, G.; Vigneri, R. Diabetes and cancer. Endocr. Relat. Cancer 2009, 16, 1103-1123. [CrossRef] [PubMed]

70. Giovannucci, E.; Harlan, D.M.; Archer, M.C.; Bergenstal, R.M.; Gapstur, S.M.; Habel, L.A.; Pollak, M.; Regensteiner, J.G.; Yee, D. Diabetes and cancer: A consensus report. Diabetes Care 2010, 33, 1674-1685. [CrossRef] [PubMed]

71. Belfiore, A.; Costantino, A.; Frasca, F.; Pandini, G.; Mineo, R.; Vigneri, P.; Maddux, B.; Goldfine, I.D.; Vigneri, R. Overexpression of membrane glycoprotein PC-1 in MDA-MB-231 breast cancer cells is associated with inhibition of insulin receptor tyrosine kinase activity. Mol. Endocrinol. 1996, 10, 1318-1326. [PubMed]

72. Kaaks, R.; Johnson, T.; Tikk, K.; Sookthai, D.; Tjønneland, A.; Roswall, N.; Overvad, K.; Clavel-Chapelon, F.; Boutron-Ruault, M.-C.; Dossus, L.; et al. Insulin-like growth factor I and risk of breast cancer by age and hormone receptor status-A prospective study within the EPIC cohort. Int. J. Cancer 2014, 134, 2683-2690. [CrossRef] [PubMed]

73. Granados-Principal, S.; Quiles, J.L.; Ramirez-Tortosa, C.L.; Sanchez-Rovira, P.; Ramirez-Tortosa, M.C. Hydroxytyrosol: From laboratory investigations to future clinical trials. Nutr. Rev. 2010, 68, 191-206. [CrossRef] [PubMed]

74. Trichopoulou, A.; Costacou, T.; Bamia, C.; Trichopoulos, D. Adherence to a Mediterranean diet and survival in a Greek population. N. Engl. J. Med. 2003, 348, 2599-2608. [CrossRef] [PubMed]

75. Fayyaz, S.; Aydin, T.; Cakir, A.; Gasparri, M.L.; Panici, P.B.; Farooqi, A.A. Oleuropein Mediated Targeting of Signaling Network in Cancer. Curr. Top. Med. Chem. 2016, 16, 2477-2483. [CrossRef] [PubMed]

76. Hassan, Z.K.; Elamin, M.H.; Omer, S.A.; Daghestani, M.H.; Al-Olayan, S.; Elobeid, M.A.; Virk, P. Oleuropein induces apoptosis via the p53 pathway in breast cancer cells. Asian Pac. J. Cancer Prev. 2013, 14, 6739-6742. [CrossRef]

77. Fabiani, R.; Rosignoli, P.; De Bartolomeo, A.; Fuccelli, R.; Servili, M.; Montedoro, G.F.; Morozzi, G. Oxidative DNA damage is prevented by extracts of olive oil, hydroxytyrosol, and other olive phenolic compounds in human blood mononuclear cells and HL60 cells. J. Nutr. 2008, 138, 1411-1416. [CrossRef] [PubMed]

78. Tatsch, E.; Bochi, G.V.; Piva, S.J.; De Carvalho, J.; Kober, H.; Torbitz, V.D.; Duarte, T.; Signor, C.; Coelho, A.C.; Duarte, M.M.; et al. Association between DNA strand breakage and oxidative, inflammatory and endothelial biomarkers in type 2 diabetes. Mutat. Res. 2012, 732, 16-20. [CrossRef] [PubMed]

79. Dandona, P.; Thusu, K.; Cook, S.; Snyder, B.; Makowski, J.; Armstrong, N.; Nicotera, T. Oxidative damage to DNA in diabetes mellitus. Lancet 1996, 347, 444-445. [CrossRef]

80. Weinbrenner, T.; Fito, M.; de la Torre, R.; Saez, G.T.; Rijken, P.; Tormos, C.; Coolen, S.; Albaladejo, M.F.; Abanades, S.; Schroder, H.; et al. Olive oils high in phenolic compounds modulate oxidative/antioxidative status in men. J. Nutr. 2004, 134, 2314-2321. [CrossRef] [PubMed] 
81. Parkinson, L.; Keast, R. Oleocanthal, a phenolic derived from virgin olive oil: A review of the beneficial effects on inflammatory disease. Int. J. Mol. Sci. 2014, 15, 12323-12334. [CrossRef] [PubMed]

82. Beauchamp, G.; Keast, R.S.; Morel, D.; Lin, J.; Pika, J.; Han, Q.; Lee, C.H.; Smith, A.B.; Breslin, P.A. Phytochemistry: Ibuprofen-like activity in extra-virgin olive oil. Nature 2005, 437, 45-46. [CrossRef] [PubMed]

83. Uchiyama, Y.; Suzuki, T.; Mochizuki, K.; Goda, T. Dietary supplementation with a low dose of (-)-epigallocatechin-3-gallate reduces pro-inflammatory responses in peripheral leukocytes of non-obese type 2 diabetic GK rats. J. Nutr. Sci. Vitaminol. 2013, 59, 541-547. [CrossRef] [PubMed]

84. Moral, R.; Escrich, R.; Solanas, M.; Vela, E.M.; Ruiz de Villa, C.; Escrich, E. Diets high in corn oil or extra-virgin olive oil differentially modify the gene expression profile of the mammary gland and influence experimental breast cancer susceptibility. Eur. J. Nutr. 2016, 55, 1397-1409. [CrossRef] [PubMed]

85. Donato, R.; Cannon, B.R.; Sorci, G.; Riuzzi, F.; Hsu, K.; Weber, D.J.; Geczy, C.L. Functions of S100 proteins. Curr. Mol. Med. 2013, 13, 24-57. [CrossRef] [PubMed]

86. Chavakis, T.; Bierhaus, A.; Nawroth, P.P. RAGE (receptor for advanced glycation end products): A central player in the inflammatory response. Microbes Infect. 2004, 6, 1219-1225. [CrossRef] [PubMed]

87. Nowotny, K.; Jung, T.; Höhn, A.; Weber, D.; Grune, T. Advanced glycation end products and oxidative stress in type 2 diabetes mellitus. Biomolecules 2015, 5, 194-222. [CrossRef] [PubMed]

88. Zhang, N.; Valentine, J.M.; Zhou, Y.; Li, M.E.; Zhang, Y.; Bhattacharya, A.; Walsh, M.E.; Fischer, K.E.; Austad, S.N.; Osmulski, P.; et al. Sustained NFKB inhibition improves insulin sensitivity but is detrimental to muscle health. Aging Cell 2017, 16, 847-858. [CrossRef] [PubMed]

89. De Bock, M.; Derraik, J.G.B.; Brennan, C.M.; Biggs, J.B.; Morgan, P.E.; Hodgkinson, S.C.; Hofman, P.L.; Citfield, W.S. Olive (Olea europaea L.) Leaf Polyphenols Improve Insulin Sensitivity in MiddleAged Overweight Men: A Randomized, Placebo-Controlled, Crossover Trial. PLoS ONE 2013, 8, e57622. [CrossRef] [PubMed]

90. Oliveras-Lópeza, M.J.; Bernáab, G.; Jurado-Ruizab, E.; de la Serrana, L.G.; Martínab, F. Consumption of extra-virgin olive oil rich in phenolic compounds has beneficial antioxidant effects in healthy human adults. J. Funct. Foods 2014, 10, 475-484. [CrossRef] 